Utah State University

DigitalCommons@USU

3-1-2019

\title{
Chatting Without Borders: Assessment as the First Step in Cultivating an Accessible Chat Reference Service
}

\author{
Teagan Eastman \\ Utah State University \\ McKenzie Hyde \\ Utah State University \\ Katie Strand \\ Utah State University \\ Rachel Wishkoski \\ Utah State University
}

Follow this and additional works at: https://digitalcommons.usu.edu/lib_pubs

Part of the Library and Information Science Commons

\section{Recommended Citation \\ Eastman, T., Hyde, M., Strand, K., \& Wishkoski, R. (2019). Chatting without borders: Assessment as the first step in cultivating an accessible chat reference service. Journal of Library \& Information Services in Distance Learning, 13(3), 1-22. http://doi.org/10.1080/1533290X.2019.1577784}

This Article is brought to you for free and open access by the Libraries at DigitalCommons@USU. It has been accepted for inclusion in Library Faculty \& Staff Publications by an authorized administrator of DigitalCommons@USU. For more information, please contact digitalcommons@usu.edu.

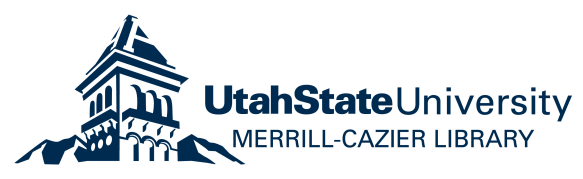




\title{
Title:
}

Chatting Without Borders: Assessment as the First Step in Cultivating an Accessible Chat Reference Service

\section{Running title:}

Chatting without Borders

\section{Author information:}

*All authors contributed equally to this paper

Teagan Eastman

Online Learning Librarian

Utah State University

McKenzie Hyde

Library Teaching Assistant

Utah State University

Katie Strand

Library Teaching Assistant

Utah State University

Rachel Wishkoski

Reference \& Instruction Librarian

Utah State University

\begin{abstract}
:
As distance education programs grow at college and universities across the country, libraries must ensure virtual reference services are prepared to meet the needs of patrons in these programs. This article describes the process and results of a 2018 chat analysis conducted at a midsize research university with a large distance education program. The authors discuss the implications of their findings, as well as their process of closing the assessment loop. By using data to inform changes to virtual reference services, chat becomes more accessible and approachable to all users regardless of location.
\end{abstract}

\section{Keywords:}

virtual reference, academic libraries, library reference services, grounded theory, data analysis, assessment 


\title{
Author information:
}

All authors contributed equally to this paper

\section{Title:}

Chatting Without Borders: Assessment as the First Step in Cultivating an Accessible Chat

Reference Service

\section{Running title:}

Chatting without Borders

\begin{abstract}
:
As distance education programs grow at colleges and universities across the country, libraries must ensure virtual reference services are prepared to meet the needs of patrons in these programs. This article describes the process and results of a 2018 chat analysis conducted at a midsize research university with a large distance education program. The authors discuss the implications of their findings, as well as their process of closing the assessment loop. By using data to inform changes to virtual reference services, chat becomes more accessible and approachable to all users regardless of location.
\end{abstract}

\section{Keywords:}

virtual reference, academic libraries, library reference services, grounded theory, data analysis, assessment

\section{Introduction}

Utah State University (USU) is a public, land-grant research institution serving over 27,000 undergraduate and graduate students. USU has a large distance education program, with nearly half the student body enrolled in courses through USU Online or at one of over 25 
regional campuses and centers throughout the state. As part of its mission to deliver high quality research support to students regardless of their location, the USU Libraries has provided a chat reference service through LibAnswers (a Springshare product) since 2013. Chat is only one of the reference formats provided by USU Libraries' Information Desk staff, who also respond to user questions in-person, over the phone, and via email. However, chat is considered an essential component of the USU Libraries' user service and engagement model, especially given its accessibility as a way for distance education users to receive synchronous help.

Despite its perceived popularity and utility for the university community, the use of the chat reference service has steadily declined since its introduction. In the first full academic year of chat reference being available (2013 - 2014) there were 3,000 chat sessions recorded in LibAnswers; in subsequent years, use has declined an average of 400 chats per year, with 1,632 chats recorded in the 2016 - 2017 academic year. While this could partially be due to reductions in the operating hours of the Information Desk (from 9 am to $9 \mathrm{pm}$ at the chat service's introduction, to 9 am to $7 \mathrm{pm}$ in 2016, to the current 9 am to $5 \mathrm{pm}$ schedule), a detailed assessment of the USU Libraries' chat service has never been conducted.

Additionally, Information Desk staffing has evolved over time. The majority of those staffing chat come from the Learning and Engagement Services unit (with several employees from other areas of the library also working shifts). These currently include nine faculty librarians, seven staff members (five of whom have MLIS degrees), and three undergraduate student workers. These student workers, our Library Peer Mentors (LPMs), receive training in both face-to-face and chat reference. Since the introduction of the chat reference service, LPMs have covered an increasing number of desk and chat shifts. Currently, LPMs cover approximately $25 \%$ of the hours chat is available. As more individuals without a degree in 
library and information science work the desk, extra training must be provided to ensure questions are being answered properly, both in terms of content and in terms of the way the chat interactions are conducted. Additionally, a degree in LIS does not guarantee the ability to deliver high quality chat reference; as with any reference format, strengths and weaknesses differ across individuals. Given the decrease in chat sessions, variation among staff in chat experience and skill, and the importance of the reference format to distance education users, assessing the scope and service quality of chat reference was clearly necessary.

In Spring 2018, a team from the Learning and Engagement Services unit at USU Libraries analyzed a year's worth of chat transcripts (over 1,600) from fall semester 2016 to the end of summer semester 2017. ${ }^{1}$ A basic goal of our project was to identify general use patterns of the chat reference service, including busy periods, chat durations, and user demographics. Because library staff did not consistently track demographics for chat interactions (explained further in the Methods section), we recoded as much of this information as we could derive from the transcripts. The primary goal of our study, however, was to examine the types of questions users were asking and assess how these questions were being responded to. We hoped to establish trends in user and responder (library staff member working chat) behaviorparticularly in the domains of user satisfaction, responder approachability, and the presence of instruction and reference interview questions - in order to identify areas for improvement. This paper describes our study's methodology and findings and discusses changes implemented to improve chat reference service at USU Libraries.

\section{Literature review}

\footnotetext{
${ }^{1}$ This study was approved by the [Name of University] Institutional Review Board, Protocol \#8997.
} 
Virtual reference services emerged with the invention of email and have become a central component of library reference services over the last twenty years. One of the most prevalent virtual reference services is synchronous chat interactions between librarians and patrons. As chat services are highly visible, widely used, and contain a complete record of the interaction between patrons and library staff, librarians have a clear incentive to analyze the quality and effectiveness of their chat services. Thus, the literature is teeming with chat analysis studies that scrutinize quality, patron satisfaction, value, and instruction present in chat reference interactions (Keyes \& Dworak, 2017; Brown, 2017; Valentine \& Moss, 2017; Devlin, Stratton, \& Currie, 2007; Lancaster, Yen, Huang \& Hung, 2007).

There is a body of literature about sampling virtual reference transactions in general (e.g., Cullen \& Gray, 1995; Murgai, 2011), and one approach to chat analysis projects is to take a sample of chat transcripts in a given period (e.g., Jacoby, Ward, Avery \& Marcyk, 2016; Valentine \& Moss, 2016). Other researchers have opted to analyze transcripts from an entire academic quarter (e.g., Belanger, et al., 2016) or year (e.g., Mungin, 2017). In our case, a random sample of transcripts was neither preferable nor necessary; analyzing the academic year's worth of transcripts was fairly uncomplicated with all four members of the research team participating in coding. This allowed us a holistic view of the service without concerns about representativeness of a sample.

While many studies focus on one quality present in chat transcripts, such as instruction or the presence of reference interview questions, several have taken a more comprehensive approach. These studies look at a bigger picture to identify gaps or problems, thus informing potential trainings for library employees or long-term changes to chat services (Luo, 2009; Mungin, 2017; Baumgart, Carillo, \& Schmidli, 2016; Fuller \& Dryden, 2015). The goal for our 
study was to develop a baseline understanding of chat interactions - how, when, and why patrons use our chat service - and to use that understanding to apprise staff trainings and develop institutional best practices. Our approach leveraged best practices and analytic approaches from the literature while considering our institutional context.

\section{Methods}

Our initial dataset consisted of 1,632 chat transcripts automatically collected by LibAnswers from August $1^{\text {st }}, 2016$ to July $31^{\text {st }}, 2017$. The first step in our de-identification process was to replace IP addresses with numerical transaction IDs. We then contacted any individuals (chat users and library staff responders) who were identifiable in the dataset (by name, email, or student ID number) with an opt-out form allowing them to request to be removed from the study. Transcripts from individuals who chose to opt-out were removed from the dataset, though this only included three transcripts. In cases when a user or library staff member provided a name or other identifiable information during the chat, we replaced that information with "patron" and "librarian," respectively. Student employees and the majority of library staff $\log$ into the chat reference system using a general account. Because of this, it is not possible to identify whether or not the library responder is a student in most of our chats. Frequent substitutions mean actual shift coverage can vary substantially from the printed desk schedule. In addition, we did not enter the project with the assumption that all "bad" chats would be done by student employees; though we noted that our staffing model has shifted toward more student coverage over time, all employees - ourselves included - could benefit from identifying areas of improvement in our chat reference service.

After deleting any chats belonging to those who opted out and anonymizing the rest, we also removed any transcripts that were clearly jokes, hang-ups (where a user started a chat but 
never responded further), class demonstrations (where a librarian demonstrated the chat service for a class), in-house (where two library staff members communicated through chat), or a test (where a library staff member tested the chat system or conducted training chats with student workers). ${ }^{2}$ This left us with 1,410 transcripts to code, which we divided evenly among the four members of our research team. Three of the four research team members staffed the chat reference service during the time period of our dataset, while one member began after the collected time period. While it is likely that members of the research team coded chats for which they were the library responder, the process of removing identifying information from chats was completed by a student employee. Self-evaluation was minimal and we do not feel it significantly impacted our analysis. The members of the research team conducted a small portion of the chats, and recognizing them would have required team members to remember specific details about chats conducted anywhere from $6-18$ months prior.

After examining the range of codes used in other chat analysis studies, we selected the extensive codebook developed by Mungin (2017) as a model for the categories of qualitative codes we were interested in exploring: content analysis (e.g., what questions the chat users ask), user behavior (e.g., demonstrated satisfaction), and responder behavior (e.g., amount of instruction provided). We then consulted our transcripts to develop specific codes within these categories that captured the aspects of our sample we wanted to understand. Our process of codebook development is summarized in Table 1 . We combined these codes with demographic information to form our final codebook (see Appendix A). ${ }^{3}$

\footnotetext{
${ }^{2}$ We would like to thank [Name of Student], a [Name of University] Library Peer Mentor, for his assistance with transcript de-identification and removal of joke, hang-up, demo, in-house, and test chats.

${ }^{3}$ LibAnswers automatically saves all chat transcripts, but demographic information is not attached to them unless they are manually saved as reference transactions by the chat responder. Most chat responders did not save transcripts as reference transactions. Thus, a comprehensive analysis of chat user demographics required us to recode demographic information and the numerical transaction type for each transcript. This was ultimately beneficial, as we could ensure consistency in transaction type coding and we could add some demographic nuance to our user
} 
In order to streamline coding, we built our codebook into a Qualtrics survey. This choice of platform allowed us to code simultaneously, display relevant questions only (through survey logic), and run simple analyses in the platform after all the transcripts had been coded. We exported metadata about the transcripts (time and date, wait time, chat duration, and message count) from LibAnswers into Excel.

\section{[Insert Table 1]}

\section{Results}

Regardless of the format, all reference interactions at the USU Libraries Information Desk are logged as a transaction Type 1,2, or 3. In order to facilitate comparison to other reference analyses—and to capitalize on shared understanding among our staff—we coded each chat transcript with these general transaction types before coding the content of the chat in greater detail. As our codebook explains, Type 1 transactions are general questions, such as directions, hours, and printing. Type 2 transactions cover a wide variety of content, including known item searches and library policies and procedure. Research-related questions are Type 3 , encompassing many parts of the research process from topic exploration, to source search and discovery, to citation questions. Only $9.71 \%$ of our chats were a Type $1,57.59 \%$ were a Type 2 , and $32.70 \%$ were a Type 3 . Figure 1 shows how these chat transaction types were distributed throughout the entire academic year. The majority of Type 1 questions occurred at the beginning of the fall and spring semesters. This pattern correlates with the influx of new students and their need for general library information and directions. Although Type 1 questions were prevalent early in the semester, Type 2 questions were still the highest in all parts of the year except for the

categories. Instead of a blanket "Unknown" patron category, for example, we added an "Unknown student" category for the times when the patron was clearly a student but not clearly an undergraduate, graduate, or concurrent enrollment (high school) student. 
middle of the spring semester. The middle of the spring semester as well as the middle of the fall semester showed the most significant increase in Type 3 questions. Research questions declined substantially towards the end of each semester.

\section{[Insert Figure 1]}

The majority of our chat users were USU students of some kind $(61.16 \%)$, though as Table 2 shows, a large percentage of these were not identifiable as specifically undergraduate or graduate. Students named specific courses they were seeking help with in only $16.49 \%$ of the transcripts, but overall, the range of chat subject areas reflected the range of classes and degree programs offered by the university. If the chat user specifically stated their location as one of our Regional Campuses or USU Online, we tracked that data; otherwise, charts were coded as "no or unknown." The result was that only $12.65 \%$ of students were confirmed as Regional Campus/Online. Since nearly half of our student population falls into this category and since library staff rarely asked explicitly for user location, this percentage likely significantly underrepresents the actual number of Regional Campus/Online students using our chat service.

\section{[Insert Table 2]}

In order to gain a more detailed view of the questions chat users asked, we coded specific chat content areas (see Table 3). Known item requests (with or without access issues) were our most common type of question, followed by research questions, and then questions about library services. At $63.02 \%$ of research questions, Level 1 questions (topic exploration and narrowing, a first attempt at finding sources for a topic, and basic database instruction) were most common, indicating that most chat users with these questions are coming to chat early in their research process. Level 2 research questions (users who had already done some research and needed help locating additional sources) were the next most frequent, followed by Level 3 (using sources, 
including annotated bibliography and literature review questions, writing questions, and citation questions). ILL was the library service users asked about the most (41.40\% of the "Library service" code), followed by circulation questions (24.73\%). Chats that were coded as having "other/uncommon" content were far ranging — examples included questions about class registration and advising, specialty printing on campus, how to return books to the bookstore, tutoring, the Testing Center, and library jobs. Importantly, 44.96\% of questions from Regional Campus/Online users were research questions, compared to only $32.15 \%$ of Logan campus]/unknown questions.

\section{[Insert Table 3]}

Our final area of analysis focused on how chat responders answered questions and interacted with users. We coded chats for three errors: wrong information given, times when the user was referred too quickly, and missed referrals. The first error code - wrong information given - was only applied in 56 cases (3.97\% of chats). Sometimes the wrong information was simply not enough information, but the most common errors fell into the following categories: incorrect referral information, incorrect information about library policies, poor research instruction, and generally vague information not helpful to the user. We identified 351 chats (or $24.89 \%$ of our total dataset) in which referrals were made. When a user was referred, $45.01 \%$ of the time it was to another library staff member, $39.32 \%$ to a general library department, and $15.67 \%$ to a place outside the library (such as the registrar, bookstore, or writing center). We found that referrals were made too quickly only $1.97 \%$ of the time. Beyond the 351 chats in which a referral was made, 99 additional chats were coded as missed referrals. In total, therefore, 450 chats should have involved a referral. The 99 chats that did not receive a referral represent a failure to refer $22 \%$ of users who would have benefitted from being connected with another 
person. Referrals are particularly important to our Regional Campus/Online students, as chat is one of the only venues for introducing these individuals to subject matter experts.

In terms of how library staff interacted with users, we found that approachability scored a Level 2 or $391.17 \%$ of the time. Only $8.83 \%$ of chats were a Level 1, with an overly robotic tone, lack of a statement of welcome, extreme gaps in the conversation, or other off-putting responder behaviors. The majority of our chats $(67.81 \%)$ were a Level 2, which meant responders were not rude, but were not overly welcoming either. Responders demonstrated interest, empathy, encouragement, and engagement (e.g., with exclamation points and emoticons) $23.36 \%$ of the time.

The amount of instruction chat responders provided varied according to question type. Detailed instruction was not appropriate or necessary in all chat interactions; directional questions, for example, were often best served by a quick response, but more in-depth questions with research elements were enhanced when desk staff engaged in step-by-step instruction. We coded the instruction present in our chat transcripts in three levels. A Level 1 was a quick answer without explanation, a Level 2 was an attempt at instruction with skipped steps (either because unnecessary, not provided by the responder, or the patron did not reciprocate), and a Level 3 was a thorough, step-by-step explanation that a chat user could later recreate. Research questions became our primary focus in regard to level of instruction as it seemed most relevant in those circumstances. In order to assess the instruction provided for research questions specifically, we analyzed the level of instruction provided at each of the levels of research question. For research questions coded as a Level 1, 43.06\% of users received a quick answer while only $27.43 \%$ received step-by-step instruction. The type of instruction provided for Level 2 research questions was almost evenly distributed, with an attempt at instruction slightly prominent at $35.96 \%$. 
$43.64 \%$ of Level 3 research questions received a quick answer, while $38.18 \%$ received step-bystep instruction. The instruction provided to Regional Campus/Online users was most likely to be a quick answer $(48.06 \%)$, and was step-by-step only $30.23 \%$ of the time. Since chat reference serves as one of the few synchronous opportunities librarians have to teach these students research skills, this amount of step-by-step instruction seems problematic. Finally, 27.13\% of research-focused chats did not contain any reference interview questions ("What have you tried?", clarifying questions, open-ended questions, or “Can I help with anything else?") in the library staff member's response.

\section{[Insert Figure 2]}

We also analyzed user satisfaction in order to assess user reactions to chat practices. Unfortunately, the data collected makes us hesitant to heavily incorporate user satisfaction data into our analysis, which could have a significant impact on our chat service. The majority (64.25\%) of chat users responded with a "thanks" even if incorrect information was provided or even if the librarian did not meet their real need. In chats where no reference interview questions were present, $83 \%$ of users were still polite or showed gratitude, and only $1.3 \%$ of our chat users showed dissatisfaction. Additionally, only 38 transcripts were coded to indicate that users had "unreasonable expectations" of the chat reference service due to misperceptions about its intended use or a wish for instant gratification to cure procrastination. This places responsibility for the improvement of the chat interaction in the hands of staff; our users are, overall, polite and understand the purpose of the service.

\section{Discussion}

Our analysis uncovered four areas in which we need to strike a better balance: 1) the questions we ask our users, 2) our approachability and friendliness as chat responders, 3) 
referrals, and 4) the level of instruction we provide in chat interactions. The type and frequency of questions is quite nuanced, so analyzing them provided us with much-needed insight into how we approach chat for on-campus users and regional campus users alike.

While it is possible that many chat users utilize the service in order to receive quick answers, our findings indicate that if library staff asked more questions it would improve many, if not all chats. This is because without asking important clarifying questions library staff cannot fully understand patrons' information needs and tailor responses to their specific circumstances. We found that the majority of our patrons were labeled "Unknown" (see Table 3), meaning library staff members do not know their status (student, faculty, community member) or location (Logan campus, regional campus, or online) and therefore cannot fully cater to these individuals' specific needs. For example, in one research-focused chat, a librarian suggested only physical books for research, not online resources - but the patron revealed that they were a Regional Campus student and left the chat. Therefore, the patron left the interaction unaware of the many online resources available to them that could assist in their research needs, which is the opposite of our goal with chat reference. This mistake could have been avoided if the librarian had confirmed the student's campus at the beginning of the chat. In order to provide accessible chat service to all patrons, we need to employ strategic question negotiation tactics in order to strike the balance between providing quick service and fully meeting the patrons' needs.

An additional challenge to our chat reference service is that chats lack the contextual clues that often put patrons at ease and make librarians more approachable. When assisting library patrons virtually, librarians are unable to offer a reassuring nod or an inviting smile which often dispel library anxiety. Chat interactions scored as a Level 2 for responder approachability could be interpreted as not friendly without the presence of body language. Level 2 chats 
occurred when librarians exhibited a willingness to help but lacked the empathy, encouragement, and enthusiasm present in a Level 3 chat. Level 3 chats included empathetic text such as "That's frustrating" or "I'm sorry that it isn't going well". Many librarians who reached a Level 3 also let users know that their questions are welcome and valid by using phrases such as "No problem, we're here to help!" or "Come back if you have more questions." The difference between a Level 2 and a Level 3 could mean the difference between a user coming back or not. We want users to view our chat reference service as a constant and consistent resource that they can come back to time and time again. However, users may be hesitant to return, as only $23.36 \%$ of our chats were a Level 3. Trainings resulting from this study included examples and scenarios for text-based ways to reach a Level 3 in hopes that librarians will employ them in future chat interactions. A handful of phrases that demonstrate interest and empathy like those previously mentioned are readily available for responders in our current chat system in the form of canned responses. Increased usage of these canned responses could have a significant impact in establishing a consistently high level of approachability. Librarians and students were reminded of our available responses and how to use them in future chats during trainings.

While our findings indicate that we do not tend to refer users too quickly, we do miss too many referrals. This could be due to a number of reasons, but the most likely is that the responder assumed the user did not need additional assistance (the expertise of a subject librarian, for example). Referrals are an area for balance. It is important to not bounce the patron around or overburden colleagues by not attempting to answer general questions. But it is also important to extend the offer of specialized help or additional support, and then help the patron make that connection. When a referral was provided in our chats, they were often just names and emails. We could improve the overall patron experience by having better training and protocols 
for referrals, including ways to facilitate and track them (perhaps within the LibAnswers platform itself). This would provide a more seamless, integrated experience for our users as well as closure for users and library staff.

Similar to chat analyses conducted at other institutions, our findings indicate that we struggle to find the balance between providing research instruction and quick service to our patrons (Van Duinkerken, Stephens, \& MacDonald, 2009; Valentine \& Moss, 2017). By providing research instruction within the chat, librarians are building information literacy skills that can support future research endeavors. This is especially important to regional campus and online patrons as chat is their main venue for receiving synchronous research assistance from library staff. The nature of chat reference service, however, causes librarians to question whether users want step-by-step research instruction or would prefer quick answers (Gronemyer \& Deitering, 2009; Desai \& Graves, 2006). In their 2016 study, Jacoby, et al. discovered that students were open to instruction during chat reference when in the initial stages of developing research questions and delving into subject research. However, attempting to uncover whether our users preferred quick answers or research instruction proved challenging. Cross analysis of instruction level codes with user satisfaction showed that $45 \%$ of patrons who showed extreme gratitude (satisfaction Level 4) received a quick answer response from the library responder, while $38 \%$ of patrons who received step-by-step instruction showed extreme gratitude. Along the same vein, $56 \%$ of patrons who received step-by-step instruction showed only a satisfaction Level 3 which indicates a polite "thanks." However, this analysis does not definitively prove user preference due to the prevalence of patrons who consistently reply with a polite "thanks" whether or not the responder actually helped them. Additional research, perhaps in the form of 
surveys or focus groups, is needed to determine our users' preference on the level of instruction presence in chat reference.

While additional information is needed to uncover whether our users prefer quick answers to instruction, it is clear from our findings that the use of reference interview questions could help reduce the amount of wrong or irrelevant information distributed to our users. Our findings indicated that $40 \%$ of transcripts coded as a Type 2 or 3 did not contain any reference interview question in the librarian's response. This is problematic given the presence of wrong or irrelevant information in our sample. The use of question negotiation could reduce the presence of irrelevant keywords, for example, or issues of pointing users to databases or venues not related to their research query.

\section{Conclusion}

We see assessment as the first step in a process of improvement, and as such, sought ways to share our findings through internal professional development avenues. After analyzing our data, we presented our findings to library staff in two trainings related to the project. Both took place toward the beginning of fall semester as a kickoff for a new year and coincided with a major change in our Information Desk. For a semester pilot, the Information Desk merged with the Circulation Desk, which meant this was an opportune time to remind staff about some core elements of public service - including chat reference work. Our first training was for the Learning \& Engagement Services staff (twelve degreed librarians and two library staff), who work a large portion of desk and chat shifts, at one of our first department meetings of the academic year. In it, we discussed our results and then co-developed a set of chat best practices by having staff work in small groups with sample transcripts from our dataset. We selected a range of examples to prompt discussion and summarized key takeaways in a chat best practices 
resource and infographic (see Appendix B). This resource was distributed to all chat staff and posted at the Information Desk to serve as a reminder during shifts. Our second training was an interactive session with Library Peer Mentors, our student employees who staff chat, but do not attend Learning \& Engagement Services department meetings. We shared our list of best practices, practiced chatting using common scenarios as prompts, and debriefed in discussion afterward.

The decision to offer two different training sessions allowed us to cater to the needs and experience of our two different audiences. We wanted to take advantage of the expertise of our librarians by focusing the majority of their training on developing a shared set of best practices. In comparison, we devoted a significant amount of our training with student employees on best practices and how to answer frequently asked questions. The Learning \& Engagement Services department at the USU library utilizes a highly collaborative model, and so these trainings were expected as a follow-up to the project. Furthermore, informal feedback from attendees was positive and indicated that the trainings were useful and our overall findings have been shared beyond the Learning \& Engagement Services department to help with broader assessment projects. Finally, to improve referrals, the library expanded the list of experts on the "Book a Librarian" page of the website and is investigating options for a more robust and library staffinitiated referral process.

Along with our efforts to close the assessment loop by making the service improvements described above, our study did have limitations and areas for further research remain. The main limitation was our decision to utilize a locally developed codebook. Our codebook is specific to our institution and research goals, and it is therefore difficult to make direct comparisons to other chat analysis findings. Another limitation was that we did not formally assess staff's experiences 
in the trainings in hopes to more immediately improve our chat reference service. A future reevaluation of the chats themselves after this project and trainings would demonstrate if staff adopted our best practices and utilized our trainings. Further research could explore reasons behind chat responders' decisions to refer a patron or not, take a more nuanced approach to assessing patron satisfaction (through a detailed post-chat survey), and analyze the impact of the desk merge on the quality of our reference services in all formats. Further research could also assess chat users' desired level of instruction to aim for a better balance, or assess changes in chat questions and patterns over a longer period of time.

While chat analysis projects provide ample opportunities to learn about users and identify areas for improvement, they can be time- and labor-intensive projects. For those interested in conducting a chat analysis project at their own institution we offer the following recommendations:

- Use a codebook that works for your institutional context. Think about your purpose - what are you trying to learn? Choose, create, or modify a codebook that relates to your specific needs and institution. Do a run through with sample chats from your institution to refine codes and provide examples.

- Explore coding platforms. Choose a coding platform that fits the scale and purpose of your project, the size of your sample, and individual or team needs.

- Allow time for coding. Each chat took our team approximately 4 minutes apiece to analyze with total coding lasting one month. Give yourself time to code to ensure you have to time to properly code the chats. 
- Consider a team-based approach. Depending upon the size of your sample, a team approach can help divide the workload and provide multiple perspectives that will be helpful during brainstorming the codebook and analyzing results.

- Learn from your results and the process. Be prepared to learn not only from the chats you analyze, but from other team members' perspectives during analysis. Projects like these can serve as roundabout professional development opportunities for strengthening your own skills in delivering chat reference, project management, and research design.

While time consuming, authentic assessment of chat reference is necessary to check assumptions about the value and use of virtual reference services. Chat is not something extra or done on the side of "real" reference work done in-person. Especially given our large population of distance learners, the assumption that a user has an alternative for getting synchronous help is flawed. This project is an example of the importance of revisiting and using real chat interactions to challenge assumptions and inform changes to create an approachable and accessible chat reference service, regardless of location. 


\section{References}

Baumgart, S., Carillo, E., \& Schmidli, L. (2016). Iterative chat transcript analysis: Making meaning from existing data. Evidence Based Library and Information Practice, 11(2), $39-55$.

Belanger, J., Collins, K., Deutschler, A., Greer, R., Huling, N., Maxwell, C., ... Chin Roemer, R. (2016). University of Washington Chat Reference Transcript Assessment Executive Summary. Seattle, WA: University of Washington. Retrieved from https://www.lib.washington.edu/assessment/projects/chat-reference-assessment-project2014-2016-final-report

Brown, R. (2017). Lifting the veil: Analyzing collaborative virtual reference transcripts to demonstrate value and make recommendations for practice. Reference \& User Services Quarterly, 57(1), 42-47.

Cullen, R., \& Gray, A. (1995). A method for taking a reliable statistical sample of reference enquiries in a New Zealand Public Library system. Journal of Library Administration, 22(1), 113-123.

Desai, C. M., \& Graves, S. J. (2006). Instruction via Instant Messaging reference: What's happening? The Electronic Library 24(2), 174-189.

Devlin, F., Stratton, J., \& Currie, L. (2017, November). Not just Q\&A: Teaching through digital reference. In C. J. Ury, F. Baudino, \& S. G. Park (Eds.), Brick \& Click Libraries:

Proceedings of an Academic Library Symposium (pp. 124-130). Maryville, MO: Northwest Missouri State University.

Fuller, K., \& Dryden, N. H. (2015). Chat reference analysis to determine accuracy and staffing needs at one academic library. Internet Reference Services Quarterly, 20(3-4), 163-181.

Gronemery, K., \& Deitering, A. M. (2009). "I don't think it's harder, just that it's different" librarians' attitudes about instruction in the virtual reference environment. Reference Services Review, 37(4), 421-434.

Jacoby, J., Ward, D., Avery, S. \& Marcyk, E. (2016). The value of chat reference services: A pilot study. portal: Libraries and the Academy, 16(1), 109-129.

Keyes, K., \& Dworak, E. (2017). Staffing chat reference with undergraduate student assistants at an academic library: A standards-based assessment. The Journal of Academic Librarianship, 43, 469-478.

Lancaster, S., Yen, D., Huang, A. H., \& Hung, S.Y. (2007). The selection of instant messaging or e-mail: College students' perspective for computer communication. Information Management \& Computer Security, 15(1), 5-22. 
Luo, L. (2009). Effective training for chat reference personnel: An exploratory study. Library \& Information Science Research, 31, 210 - 224.

Mungin, M. (2017). Stats don't tell the whole story: Using qualitative data analysis of chat reference transcripts to assess and improve services. Journal of Library \& Information Services in Distance Learning, 11(2), 25-36.

Murgai, S. R. (2006). Reference use statistics: Statistical sampling method works. The Southeastern Librarian, 54(1), 45-57.

Valentine, G., \& Moss, B. D. (2017, March). Assessing reference service quality: A chat transcript analysis. In D. M. Mueller (Ed.), At the Helm: Leading Transformation: The Proceedings of the ACRL 2017 Conference, March 22-25, 2017, Baltimore, Maryland (pp. 67-75). Chicago, IL: Association of College and Research Libraries.

Van Duinkerken, W., Stephens, J. \& MacDonald, K.I., (2009). The chat reference interview: Seeking evidence based on RUSA's guidelines: A case study at Texas A\&M University Libraries. New Library World, 110(3-4), 107-121. 


\section{Appendix A: Codebook}

\begin{tabular}{|c|c|c|}
\hline \multicolumn{3}{|c|}{ Introduction } \\
\hline Code & Possible responses & Definition or notes \\
\hline Coder & Name & \\
\hline Transcript ID & Number & \\
\hline Chat status & Joke & \\
\hline & Hang-up & \\
\hline & Class demonstration & \\
\hline & In-house & \\
\hline & Test & \\
\hline & Real & \\
\hline
\end{tabular}

\begin{tabular}{|c|c|c|}
\hline \multicolumn{3}{|c|}{ Demographics } \\
\hline Transaction type & 1 & $\begin{array}{l}\text { Directions, hours, printing, things you know off top of } \\
\text { your head (do you have computers/scanners/fax) }\end{array}$ \\
\hline & 2 & $\begin{array}{l}\text { Policies, procedures (how do you check out a book; } \\
\text { reserve study room; ILL); Known item searching only, } \\
\text { troubleshooting/access (without teaching) }\end{array}$ \\
\hline & 3 & $\begin{array}{l}\text { Citation questions, research, narrowing a topic/topic } \\
\text { exploration, etc. }\end{array}$ \\
\hline \multirow{2}{*}{ Regional campus/online } & No or unknown & \\
\hline & Yes & \\
\hline \multirow[t]{8}{*}{ Patron type } & High school & \\
\hline & Undergraduate & \\
\hline & Graduate & \\
\hline & Unknown student* & *Use this rather than assuming undergrad or grad \\
\hline & Faculty/staff & \\
\hline & Alumni & \\
\hline & Community & \\
\hline & Unknown & \\
\hline \multirow[t]{2}{*}{ Course } & ENGL 2010 & \\
\hline & Other: [TEXT] & $\begin{array}{l}\text { Course number (ENGL 1010) or general department } \\
\text { ("I'm looking for articles for my Biology class") }\end{array}$ \\
\hline
\end{tabular}

\begin{tabular}{|l|l|l|}
\hline \multicolumn{3}{|c|}{ Content Analysis } \\
\hline Content (select all that apply) & Complaint about library & Not complaint about chat service \\
\hline & Building/policies & \\
\hline & Library service' & \\
\hline & $\begin{array}{l}\text { Technology } \\
\text { troubleshooting }\end{array}$ & \\
\hline & $\begin{array}{l}\text { Known item request or } \\
\text { search without access issues }\end{array}$ & \\
\hline & $\begin{array}{l}\text { Known item request or } \\
\text { search with access issues }\end{array}$ & \\
\hline & Research & \\
\hline $\begin{array}{l}\text { 'If "Library Service" is } \\
\text { selected, what library } \\
\text { service? (select all that apply) }\end{array}$ & Other/uncommon: [TEXT] & \\
\hline & Circulation & \\
\hline
\end{tabular}




\begin{tabular}{|l|l|l|}
\hline & SCA & \\
\hline & Data & \\
\hline & ILL & e.g., schedule a class, tour, OER \\
\hline & LES & Other: [TEXT] \\
\hline $\begin{array}{l}\text { 2If "Research" is selected, } \\
\text { what level of research? }\end{array}$ & Level 1 & $\begin{array}{l}\text { Topic exploration/narrowing, need sources for a topic, } \\
\text { database instruction }\end{array}$ \\
\hline & Level 2 & Have some sources, need help finding more \\
\hline & Level 3 & $\begin{array}{l}\text { Using sources: Citation, synthesis, annotated } \\
\text { bibliography, lit review, writing }\end{array}$ \\
\hline
\end{tabular}

\begin{tabular}{|c|c|c|}
\hline \multicolumn{3}{|c|}{ User Behavior } \\
\hline Satisfaction & Level 1 & $\begin{array}{l}\text { Active anger/dissatisfaction ("you made my day } \\
\text { worse," "can you help or not?") }\end{array}$ \\
\hline & Level 2 & $\begin{array}{l}\text { No emotion apparent or chat ends before statement of } \\
\text { satisfaction }\end{array}$ \\
\hline & Level 3 & Polite ("thanks") \\
\hline & Level 4 & $\begin{array}{l}\text { Extreme gratitude, exceptionally happy, } \\
\text { complimentary }\end{array}$ \\
\hline $\begin{array}{l}\text { Unreasonable expectation } \\
\text { of service }\end{array}$ & Level 1 & $\begin{array}{l}\text { Instant gratification: Want the answer, not the } \\
\text { instruction }\end{array}$ \\
\hline & Level 2 & Underestimation of time for chat interaction \\
\hline & Level 3 & Procrastination: paper is due in 2 hours, chat $=$ magic \\
\hline & Doesn't apply & \\
\hline
\end{tabular}

\begin{tabular}{|c|c|c|}
\hline \multicolumn{3}{|c|}{ Responder Behavior } \\
\hline \multirow[t]{3}{*}{ Approachability/friendliness } & Level 1 & $\begin{array}{l}\text { Robotic tone, no statement of welcome, saying you're } \\
\text { busy, extreme gaps in conversation, condescending }\end{array}$ \\
\hline & Level 2 & $\begin{array}{l}\text { Neutral, not rude but not overly welcome (e.g., } \\
\text { statement of willingness to help) }\end{array}$ \\
\hline & Level 3 & $\begin{array}{l}\text { Demonstrates interest ("what a cool question/topic"), } \\
\text { exclamation points/smileys, demonstrates } \\
\text { humor/warmth, empathy, encouragement }\end{array}$ \\
\hline \multirow[t]{3}{*}{ Referral or follow-up } & Library individual & Subject librarian or expert \\
\hline & Library department & e.g., ILL, Circulation, Gov. Info \\
\hline & Outside library & $\begin{array}{l}\text { e.g., Writing Center, Registrar, Testing Center, } \\
\text { outside university }\end{array}$ \\
\hline \multirow[t]{4}{*}{$\begin{array}{l}\text { Reference Interview (select all } \\
\text { that apply) }\end{array}$} & $\begin{array}{l}\text { What have you tried? } \\
\text { Where have you already } \\
\text { looked? Have you tried } \\
\text { [specific database]? }\end{array}$ & \\
\hline & $\begin{array}{l}\text { Clarifying questions } \\
\text { present }\end{array}$ & \\
\hline & $\begin{array}{l}\text { Open ended questions } \\
\text { present }\end{array}$ & \\
\hline & $\begin{array}{l}\text { Can I help with anything } \\
\text { else? Is there anything } \\
\text { else? }\end{array}$ & $\begin{array}{l}\text { Not the statement "Let me know if I can help with } \\
\text { anything else" }\end{array}$ \\
\hline \multirow[t]{2}{*}{ Instruction } & Level 1 & $\begin{array}{l}\text { Quick Answer: Here's a link with no explanation of } \\
\text { how to recreate }\end{array}$ \\
\hline & Level 2 & $\begin{array}{l}\text { Attempt at instruction but steps of process may be } \\
\text { skipped (because unnecessary, not given, or patron } \\
\text { isn't interested/doesn't reciprocate) }\end{array}$ \\
\hline
\end{tabular}




\begin{tabular}{|l|l|l|}
\hline & Level 3 & $\begin{array}{l}\text { Step-by-step with explanation of why: patron could } \\
\text { recreate steps later }\end{array}$ \\
\hline Errors & Wrong info given & Blatant \\
\hline & Missed referral & $\begin{array}{l}\text { Rather than try to help, moving patron not question, } \\
\text { too extreme }\end{array}$ \\
\hline & Quick referral & \\
\hline & Doesn't apply & \\
\hline
\end{tabular}




\section{Appendix B: Training resource and best practices handout}

\section{MOST COMMON WRONG INFO:}

note: sometimes the "wrong" info was simply not enough info

\section{CATEGORY}

A. Incorrect referral

B. Library policies

C. Poor database instruction

D. Extremely vague information

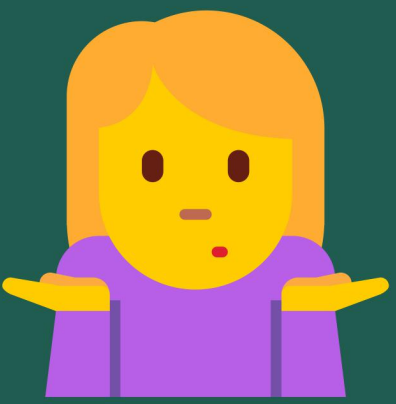

\section{EXAMPLES}

A. Told patron that librarians can't help with citations, only Writing Center can A. Gave wrong name for streaming librarian

B. Told faculty they had to purchase community library card

B. Told patron they could not pay fees online

B. Incorrect instructions on how to use materials such as ReadCube or ILL B. Told patron incorrect info about alumni access

C. Gave insufficient citation evaluation info

C. Wrong search mechanisms

C. Wrong info about accessing journals

D. Told patron to see "main office" about access to materials

D. No info on how to use the BARN or what it is

D. Confusing instructions, hard to follow 


\section{The best chats...}

- Asked clarifying questions

- Didn't assume the student's campus

- Gave thorough instruction when it was needed

- Referred to the correct person when necessary

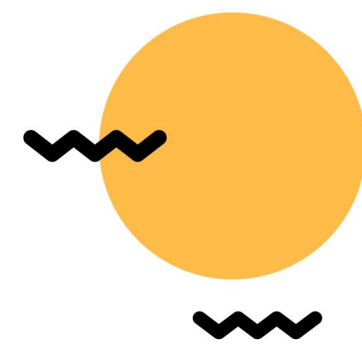

\section{Show you care}

Most patrons expressed gratitude even when they received bad information. No matter how the patron reacts, the chat usually ends on a better note when the librarian offers empathy, understanding, kindness, and a human voice--and an open invitation to ask more questions or come back later for more help.

\section{Assess their need}

Some patrons are in a hurry--they need information, and fast! It's not always easy to tell when a quick answer is better than lengthy instruction, but asking a few clarifying questions never hurts!

Psst..don't forget to track your chats!

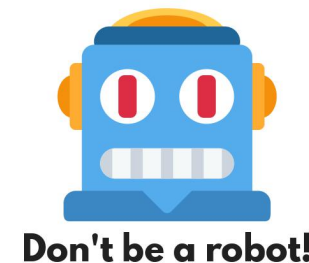

Don't be a robot!
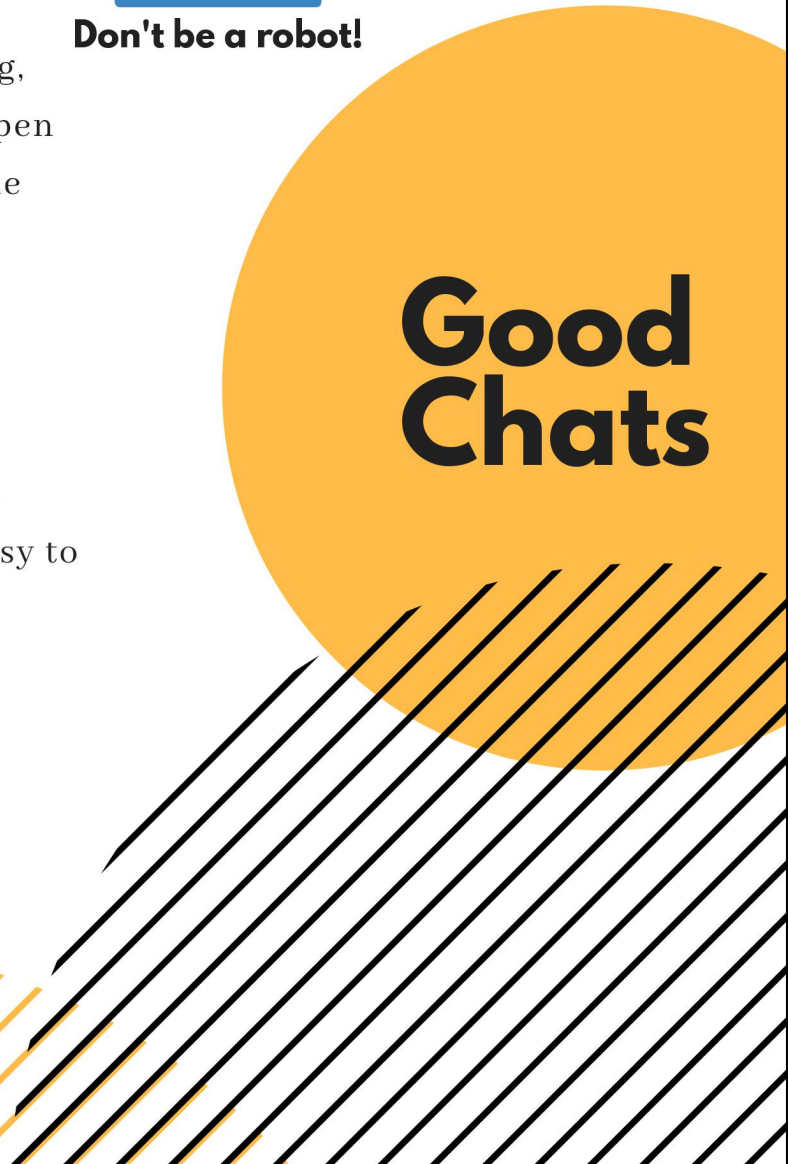


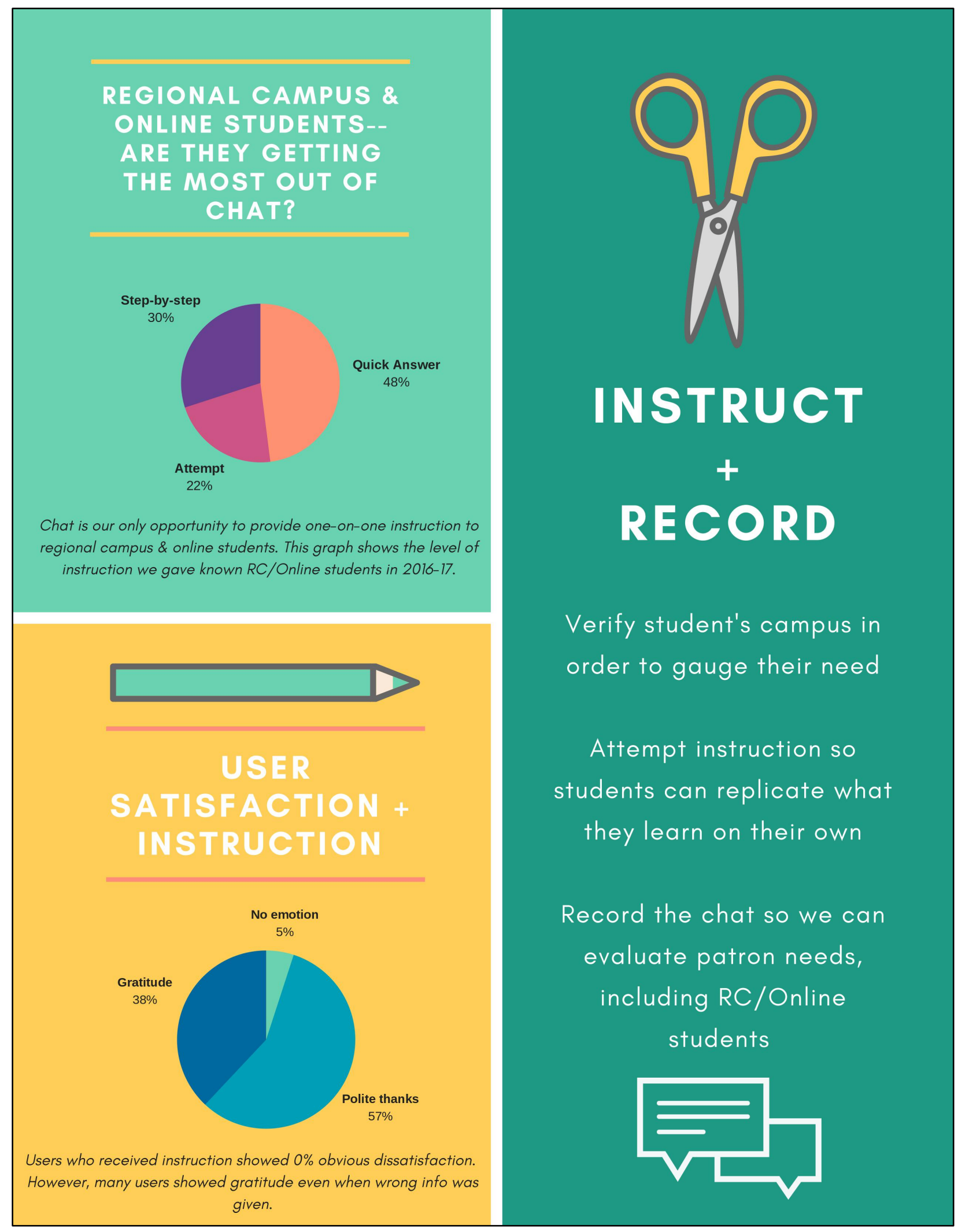

